\title{
Human-Triggered Earthquakes and Their Impacts on Human Security
}

\author{
Christian D. KLOSE ${ }^{\text {a }}$ \\ ${ }^{a}$ Columbia University, New York NY, USA
}

\begin{abstract}
A comprehensive understanding of earthquake risks in urbanized regions requires an accurate assessment of both urban vulnerabilities and earthquake hazards. Socioeconomic risks associated with human-triggered earthquakes are often misconstrued and receive little scientific, legal, and public attention. However, more than 200 damaging earthquakes, associated with industrialization and urbanization, were documented since the 20th century. This type of geohazard has impacts on human security on a regional and national level. For example, the 1989 Newcastle earthquake caused 13 deaths and US\$3.5 billion damage (in 1989). The monetary loss was equivalent to 3.4 percent of Australia's national income (GDI) or 80 percent of Australia's GDI per capita growth of the same year. This article provides an overview of global statistics of humantriggered earthquakes. It describes how geomechanical pollution due to large-scale geoengineering activities can advance the clock of earthquakes or trigger new seismic events. Lastly, defense-oriented strategies and tactics are described, including risk mitigation measures such as urban planning adaptations and seismic hazard mapping.
\end{abstract}

Keywords. Human-triggered, earthquakes, hazard, vulnerability, risk, human security, mitigation, strategies, tactics, social science, Clausewitz

\section{Introduction}

Every earthquake that ruptures somewhere on Earth is triggered by some stress perturbation in the Earth's crust. Earthquakes occur under natural conditions when tectonic stress states change (e.g., at plate boundaries, rift systems, or volcanoes). For example, natural triggering stress perturbations can result from tectonic deformation processes of drifting plates (e.g., oceanic or continental against oceanic or continental), deformations from prior volcanic eruptions, or from surface processes, including erosion (e.g., river transport) and sedimentation (e.g., river deltas). The majority of all earthquakes are triggered by natural processes and, in particular, along subduction zones surrounding the Pacific Ocean, where oceanic crust slides beneath the continents (e.g., Japan, Alaska). Most of these earthquakes do not affect human societies and economies at all. They occur deep in the interior of the Earth $(>50 \mathrm{~km})$ and their damaging seismic energy does not reach the surface. Human activities and, in particular, large-scale geoengineering constructions can also trigger earthquakes when their induced stress perturbations reach or exceed natural levels, such as daily tidal elongations (strains) of the Earth crust by the sun and the moon. Based on the concept

\footnotetext{
${ }^{1}$ Correspondence to: C. Klose, Think GeoHazards, Roseville CA, USA; christian@cdklose.com.
} 
COPY: Achieving Environmental Security: Ecosystem Services and Human Welfare.

of a human-nature coupled system [4], geoengineering activities (human system) alter stresses in the interior of the Earth's crust (nature system) that can bring preexisting faults to failure. This phenomenon is called geomechanical pollution [4, 5]. Such induced stress changes, however, may destabilize only shallow faults in the upper part of the crust $(<20 \mathrm{~km})$. Their influence tends to be small in lower parts, distant to the locations of geoengineering activities. Over the last decades, several studies about earthquakes triggered by human geoengineering actions have been published, including artificial water reservoir impoundments, deep and open-pit mining, hydrocarbon production, and fluid injections/extractions (see table 1) [6]. This paper gives a brief overview of how human activities can trigger earthquakes and how human-triggered earthquakes can affect human security [1]. Furthermore, in order to determine human security issues, this chapter outlines a logic approach as to how earthquake hazards, human vulnerabilities, and resulting risks can be estimated. Finally, von Clausewitz's early social science approach $[2,3]$ is used to provide risk mitigation and reduction strategies for human-triggered earthquakes.

\section{How Can Human Activities Trigger Earthquakes?}

Human-triggered earthquakes are a global environmental change that increases worldwide and exponentially over time (see figure 1). These earthquakes result from the mechanical response of the continental crust (i.e., elastostatic, poroelastic), due to very small induced stress perturbations stemming from geoengineering activities at the subsurface. These activities include (see figure 2):

- $\quad$ surface and underground mining (e.g., black coal),

- $\quad$ artificial water reservoirs (i.e., impoundment and/or operation stage),

- hydrocarbon production and enhanced recovery (e.g., crude oil, natural gas, steam injections),

- waste water injections deep underground (e.g., radioactive, toxic, or other hazardous liquids),

- injections of carbon dioxide deep underground (to reduce greenhouse gases into the atmosphere),

- $\quad$ geothermal energy production in greater depth (>1000 m), and

- coastal management (e.g., formation of artificial land).

Most human-triggered earthquakes rupture on preexisting faults in the Earth's crust and relatively close to the engineering activity locations $(0-30 \mathrm{~km})$. The physical triggering processes induced by the above-mentioned geoengineering activities include:

- mass removal or mass accumulation, including movement of water,

- volumetric changes (e.g., contraction of underground excavations or hydrocarbon reservoirs),

- fluid pressure changes with/without fluid flow in rock fractures/pores (e.g., dewatering and flooding of mines, reservoir impoundments),

- thermal stress changes due to temperature gradients (e.g., around injected carbon dioxide storage sites, geothermal reservoirs, underground excavations). 
COPY: Achieving Environmental Security: Ecosystem Services and Human Welfare.

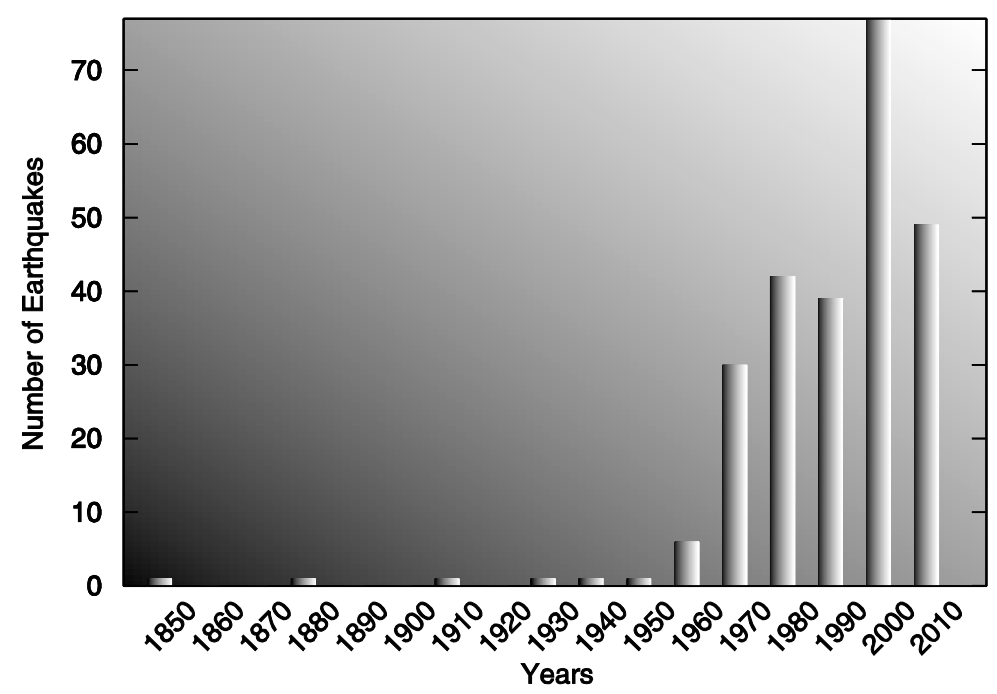

Figure 1. Number of human-triggered earthquakes versus time. The earthquake catalog is based on events with moment magnitudes $\mathrm{M}_{\mathrm{w}}>4.5$.

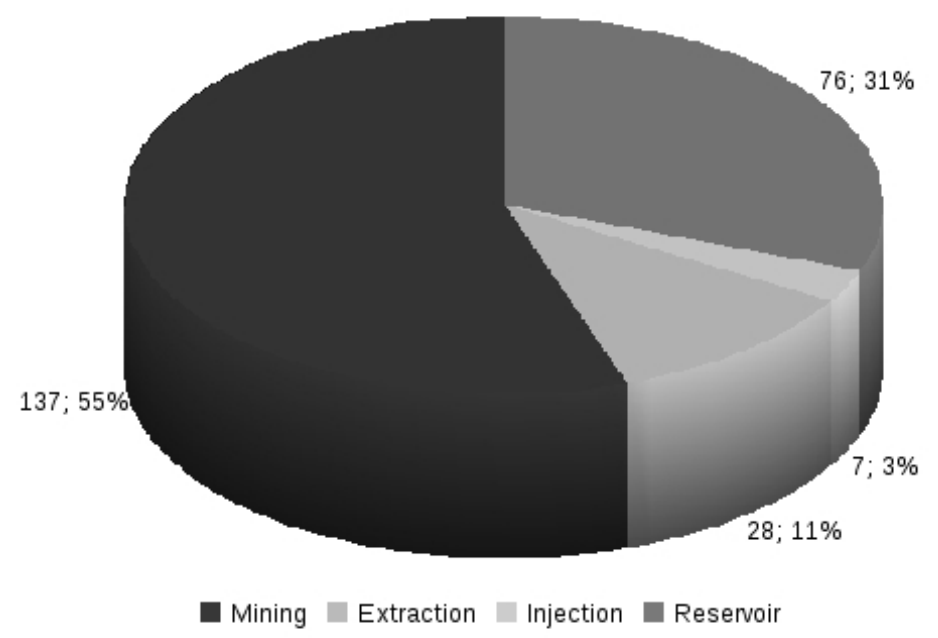

Figure 2. Number of human-triggered earthquakes with respect to the type of geoengineering activity, including mining (137), artificial water reservoir impoundment (76), oil/gas/fluid extraction (28) and fluid injections (7). The earthquake catalog is based on events with moment magnitudes $\mathrm{M}_{\mathrm{w}}>4.5$.

Statistics indicate that human-triggered earthquakes mostly occur in stable continental regions ( $>75$ percent). These regions are characterized by a very low nature-triggered seismicity $(<5$ percent), where earthquakes tend to rupture very close $(0-10 \mathrm{~km})$ to the surface [43] and tectonic conditions are stable over very long periods (e.g., thousands, tens of thousands, or millions of years). Active continental regions (e.g., California, Japan, or Turkey), in contrast, show a very low human-triggered seismicity $(<25$ percent) but a high nature-triggered seismicity ( $>95$ percent) [44]. The 
low human-triggered seismicity rate in active continental regions might also be due to the fact that less attention is paid to seismic events in these regions and that most earthquakes are assumed to be of natural origin. Earthquakes like California's M5.9 Whittier-Narrows event of 1987, for example, have shown how large-scale geoengineering activities (e.g., hydrocarbon production) can have major effects on human security $[24,25]$. This event caused US\$358 million in damage and eight fatalities (see table 1).

Overall, deformation rates of the Earth's crust in stable and active continental regions determine the recurrence frequency of earthquakes [45]. Thus, any additional triggering stress perturbation (e.g., due to human activities) on top of the natural stress accumulation (e.g., due to tectonic deformation) can advance the clock of a rupture or can trigger new seismic events. Two types of triggering mechanisms are known, a) static stress perturbations (e.g., tectonic forces, natural erosion, water accumulations in artificial reservoirs) and b) transient or dynamic stress perturbations (e.g., seismic loads from other earthquakes, seasonal water level changes in water reservoirs). Both types of triggering have different effects on the clock advancement of an expected main shock at the end of an earthquake cycle. Static changes applied early in a cycle advance the clock of the main shock much more than applied late in the cycle. In contrast, transient stress perturbations applied early in an earthquake cycle advance the clock of the main shock much less than applied late in the cycle. In addition, long-periodic waves (e.g., annual water level changes) advance the clock more than short-periodic waves (e.g., shock waves within a few seconds) [46]. Thus, two factors determine the potential of human-triggered earthquake hazard in the vicinity of geoengineering activities, a) conditions of the nature system (i.e., geological and tectonic conditions of the Earth's crust) and b) conditions of the human system (e.g., engineering operations).

Natural tectonic stresses in stable continental regions can build up over long periods of time (e.g., in Australia, Africa, and many parts of America, Europe, and Asia). These stresses initiate faults close to failure without overcoming the strength of the rock in the faults. Thus, faults in stable continental regions and, in particular, with high stress concentrations can be very earthquake trigger-sensitive due to their long earthquake cycles (e.g., >10, 000 years) [44, 47]. These regions, as mentioned above, are particularly sensitive to static or transient stress perturbations. This shows that the nature system primarily determines the potential of triggering a major earthquake.

The physical triggering processes, induced by geoengineering activities, are complicated. Some processes can bring faults close to failure, while simultaneously other processes bring the same fault away from failure. Stress alterations that destabilize a fault would bring the same fault away from failure if the geologic/tectonic conditions were different or if the involved processes were reversed. Dewatering of deep mines of the Newcastle coalfield in southwest Australia is a good example to illustrate how mass removal can bring faults close to failure [23, 4]. In contrast, seismic investigations at the Tarbela water reservoir in Pakistan showed evidence of how mass accumulation by the reservoir impoundment in 1974 locked a seismically active part of the crust in up to $70 \mathrm{~km}$ depth beneath the artificial lake (true negative example) [48]. 
COPY: Achieving Environmental Security: Ecosystem Services and Human Welfare.

\section{How Do Human-Triggered Earthquakes Affect Human Security?}

As aforementioned, the number of human-triggered earthquakes is much smaller in comparison to nature-triggered earthquakes. Their socioeconomic impacts, however, are disproportionally higher, because human-triggered earthquakes

- only occur in regions close to the geoengineering activities, i.e., rural and urbanized areas,

- $\quad$ occur mostly in naturally stable continental regions, with $>90$ percent of the world population,

- $\quad$ nucleate in very shallow depths $(0-20 \mathrm{~km})$, while damaging seismic energy can reach the Earth surface,

- $\quad$ can create lasting seismic activities in areas that were initially stable (e.g., Australia, Europe) [23, 65].

\subsection{Effects on National Security}

The 1975 M5.2 Sünna earthquake and the 1989 M5.6 Völkershausen earthquake in Germany were two severe human-triggered seismic events occurring in the same region. The Sünna earthquake caused a mesoseismal intensity of VIII resulting in a damage of about US\$131 million (2009 value). The Völkershausen event severely damaged up to 80 percent of the city of Völkershausen with a mesoseismal intensity VIII-IX [41, 26]. Besides the socioeconomic losses caused by these seismic events, they triggered political tensions between two neighboring states, the Federal Republic of Germany (FRG) and the former German Democratic Republic (GDR). ${ }^{2}$ Both countries accused each other to have triggered the earthquakes, due to deep potash mining and salt water injections, respectively [41, 26].

The political tensions between both countries led to investigations of their secret services. Evidence shows that the Ministry for State Security of the GDR (MfS, "Staatsicherheit") investigated against its own people to preempt demonstrations and potential turmoil against a) the common centralized planned mining practices and b) the communist regime, which ended its existence in 1990 after a peaceful revolution. The president of the GDR, E. Honecker, mentioned in a discussion with FRG's Minister for Special Affairs R. Seiters on 3-4 June 1989 [27]: "There has to be discussions about the rock burst of Völkershausen. Based on experts opinion in the $G D R$, ... injections of saline water on the western side can be seen as the sole reason."

The mining technology of the company "VEB Kombinat Kali," which operated in the centrally planned economy of the Marxist state GDR, continuously reduced pillar sizes in the mines to increase productivity. ${ }^{3}$ This brought the strength of the pillars down to a critical level and accelerated stress concentrations in the vicinity of the mines. On the other hand, the "Kali und Salz" mining firm in the FRG continuously injected saline wastewater in the $500-800 \mathrm{~m}$ thick overburden of the mining region and

\footnotetext{
${ }^{2}$ Both German states were founded in 1949, four years after the end of World War II. The FRG, based on principles of free-market economy, originated from the western occupied zones of the United States of America, United Kingdom, and Republic of France. The GDR was a self-declared communist state that originated from the eastern occupied sector of the Soviet Union.

${ }^{3}$ Until 1990, the GDR was the world's largest potash producer, which accounted for a quarter of the global mining output (300 million tons per year).
} 
COPY: Achieving Environmental Security: Ecosystem Services and Human Welfare.

induced annual water level changes of more than $30 \mathrm{~m}$. Both processes brought neighboring steep oriented faults to failure and caused the damaging earthquakes in Sünna and Völkershausen, including severe mine collapses. Since 1993, when the potash mining production ended in this area, more than 200 million US\$ (2009 value) were invested to refill the underground excavation in order to mitigate the hazard level for new earthquakes and mining collapses. 
COPY: Achieving Environmental Security: Ecosystem Services and Human Welfare.

Table 1. Selection of human-triggered earthquakes with significant effects on human security. Monetary losses are given for the year 2009 and (year of the earthquake); 2009 values are 3.5\%-inflation adjusted. NIA $=$ no information available.

\begin{tabular}{|c|c|c|c|c|c|c|c|}
\hline Earthquake & $\begin{array}{l}\text { Loss in } \\
\text { US\$M }\end{array}$ & $\begin{array}{l}\text { Loss in } \\
\text { Lives }\end{array}$ & \begin{tabular}{|c|} 
Seismic \\
Magnitude \\
M $\omega$
\end{tabular} & Operation & $\begin{array}{c}\text { Date } \\
\text { (dd.mm.yyyy) }\end{array}$ & State & References \\
\hline Wenchuan & $8600(8900)$ & $>69,195^{a}$ & 7.9 & Reservoir & 12.05 .2008 & China & [51-54] \\
\hline Killari & NIA & $9748^{\mathrm{b}}$ & 6.1 & Reservoir & 29.09 .1993 & India & {$[7,8]$} \\
\hline Koyna & NIA & $>200^{c}$ & 6.3 & Reservoir & 10.12 .1967 & India & {$[9,10,7,12,13]$} \\
\hline Newcastle & $6964(3500)$ & 13 & 5.6 & Mining & 27.12 .1989 & Australia & {$[23,4]$} \\
\hline Vajont tsunami & NIA & $1900-2500^{d}$ & 3.0 & Reservoir & 09.10 .1963 & Italy & {$[14,15]$} \\
\hline Whittier-Narrows & $763(358)^{\mathrm{e}}$ & 8 & 5.9 & Oil & 10.05 .1987 & USA & {$[24,25]$} \\
\hline Völkerhausen & NIA & 0 & 5.6 & Mining & 13.03 .1989 & Germany & {$[41,26]$} \\
\hline Sünna & $131(41)$ & 0 & 5.2 & Mining & 23.06 .1975 & Germany & {$[26,4]$} \\
\hline Ellalong & $87(52)$ & 0 & 5.4 & Mining & 06.08 .1994 & Australia & {$[23,4]$} \\
\hline Willmington & $71(9)$ & 0 & 3.2 & Oil & 18.11 .1949 & USA & {$[28,29]$} \\
\hline Kozani-Grevena & $65(40)$ & 0 & 6.6 & Reservoir & 13.05 .1995 & Greece & {$[30,31]$} \\
\hline Lake-Hebgen & $61(11)^{\mathrm{f}}$ & 9 & 7.1 & Reservoir & 12.05 .1959 & USA & {$[32,33,34]$} \\
\hline \multirow[t]{3}{*}{ Gazli } & NIA & $6^{g}$ & 7.0 & Natural Gas & 08.04 .1976 & Uzbekistan & {$[16,17]$} \\
\hline & NIA & NIA & 7.3 & & 17.05 .1976 & & \\
\hline & NIA & NIA & 7.2 & & 20.03 .1984 & & \\
\hline Folkestone & $34(32)^{\mathrm{h}}$ & 0 & 4.2 & $\begin{array}{c}\text { Coastal } \\
\text { Management }\end{array}$ & 28.04.2007 & England & {$[35]$} \\
\hline Klerksdorp & $24(21)^{i}$ & 2 & 5.3 & Mining & 09.03 .2005 & South Africa & {$[4]$} \\
\hline Arette & $17(4)$ & 1 & 5.7 & Natural Gas & 13.08 .1967 & France & {$[18,19,25,20]$} \\
\hline Hartebeesfontein & NIA & $>15$ & 5.0 & Mining & 21.08 .1997 & South Africa & {$[4]$} \\
\hline Arudy & $11(4)$ & 0 & 5.1 & Natural Gas & 27.02 .1980 & France & {$[18,19,25,20]$} \\
\hline Oroville & $8(2.5)$ & 0 & 5.8 & Reservoir & 01.08 .1975 & USA & [36-39] \\
\hline Basel & $7(6)$ & 0 & 3.8 & Geothermal & 12.12 .2006 & Switzerland & {$[65]$} \\
\hline Cacoosing Valley & $4(2)$ & 0 & 4.6 & Mining & 16.01 .1994 & USA & {$[22]$} \\
\hline Denver & $>4(1)$ & 0 & 5.3 & Injections & 09.08 .1967 & USA & {$[40]$} \\
\hline Lorraine Region & NIA & 1 & 4.2 & Mining & 21.06 .2001 & France & [21] \\
\hline Trona & NIA & 1 & 5.2 & Mining & 03.02 .1995 & USA & [42] \\
\hline
\end{tabular}

a. http://earthquake.usgs.gov/regional/world/world_deaths.php.

b. http://earthquake.usgs.gov/regional/world/world_deaths.php.

c. http://gbpihed.gov.in/envis/HTML/vol82/vol82-tewari.htm.

d. http://www.yearofplanetearth.org.

e. http://earthquake.usgs.gov/eqcenter/eqarchives/significant.

f. Bozeman Daily Chronicle: 28.08.1959 and 23.10.1964.

g. http://earthquake.usgs.gov/eqcenter/eqarchives/significant.

$\mathrm{h}$. Association of British Insurers.

i. http://earthquake.usgs.gov/eqcenter/eqarchives/significant.

\subsection{Effects in Economic Security}

Socioeconomic losses of human-triggered earthquakes can be very high. The 1989Newcastle earthquake in Australia was a costly earthquake triggered by deep coal mining [23, 4]. The event caused 13 deaths and damages estimated at $\$ 3.5$ billion (U.S., 1989 value), which was 3.4 percent of Australia's 1989 national income (GDI) (source: Australian Bureau of Statistics). Furthermore, the financial loss was equivalent to 60 percent of the Australian GDI growth and 80 percent of the GDI per capita growth between 1988 and 1989. It also accounted for 13 percent of the total costs of all natural disasters and 94 percent of the costs of all earthquakes recorded in Australia from 1967 to 1999 [4]. This result suggests that mining-triggered earthquakes can have 
COPY: Achieving Environmental Security: Ecosystem Services and Human Welfare.

serious impacts not only on the region closest to the geoengineering activity but also on a nation's income.

\subsection{Effects on Human Health}

It has been reported [49] that major earthquakes and long-lasting micro-earthquakeswhether nature or human triggered - do have negative psychological effects on the population. The Olivetti Heart Study [49], for example, reported on long-term psychological effects caused by earthquake tremors that occurred near Pozzuolli (Naples) in Italy between 1983 and 1984. This seven-year longitudinal scientific study, starting in 1980 after the M6.8 Irpinia earthquake, focused on evaluating risk factors for both a) coronary heart disease and b) psychological distress symptoms. Research findings of this study show that residents, experiencing the earthquakes, had suffered under long-lasting distress symptoms, such as sleep disturbance, anxiety, hostility, and depression. In addition, symptoms tend to amplify when residents experienced financial losses and/or evacuations during a major seismic event (e.g., the Irpinia earthquake).

The 2008 M7.9 Wenchuan earthquake has shown that such a devastating geohazard event can have acute impacts on brain functions in survivors, similar to symptoms observed in posttraumatic stress disorders [55]. Latest results of ongoing research studies suggest that the Wenchuan earthquake was triggered two and a half years prior to the main shock by the impoundment of a nearby $(<10 \mathrm{~km})$ artificial water reservoir of the Zipingpu dam [50-54].

Two and a half years prior to China's M7.9 Wenchuan earthquake of May 2008, up to 1.1 billion metric tons of water (3000 times the weight of the Empire State Building in New York City) accumulated with seasonal water level changes of $50 \mathrm{~m}$ in the Minjiang River Valley at the eastern margin of the Longmen Shan. The triggering perturbations of the reservoir enhanced the activity of smaller earthquakes during the impoundment cycles (see figure 3). The added stresses accounted for 10 to 60 years $(<0.6$ percent $)$ of equivalent tectonic loading on the nearby fault zone, while being strongly correlated with the coseismic slip [51, 52]. 
COPY: Achieving Environmental Security: Ecosystem Services and Human Welfare.

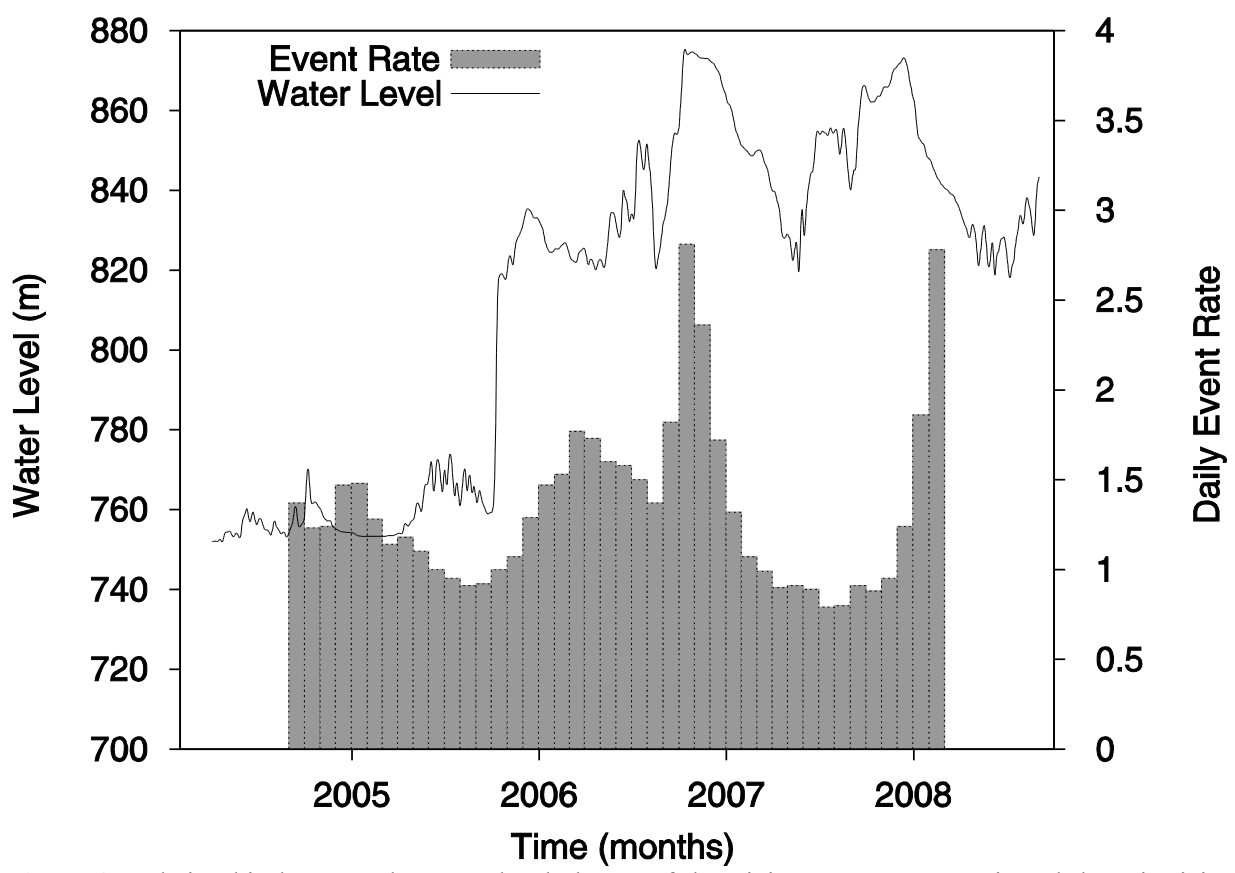

Figure 3. Relationship between the water level change of the Zipingpu water reservoir and the seismicity $(\mathrm{M}>0.5)$ of its vicinity prior the $2008 \mathrm{M} 7.9$ Wenchuan earthquake [52].

\section{Evaluation of Hazard, Vulnerability, Risk, and Uncertainty}

Estimating the occurrence $F$ and intensity (magnitude) $I$ of human-triggered earthquakes is associated with uncertainties, as for any other geohazard (e.g., storms, volcanoes, landslides). This affects the overall socioeconomic risk level $\mathrm{R}$ in space (latitude, longitude) and time ( $t$ ) and finally the human security [1] $S$ :

$$
\begin{aligned}
& R=H \cap_{\text {min }} V \\
& =(F \times I) \cap_{\text {min }} V, \\
& S=1-R .
\end{aligned}
$$

$H$ indicates the level of the hazard and $V$ the level of the socioeconomic vulnerability. Both, variables are functions of space and time: $H=H($ lat , long, $t)$ and $V$ $=V$ (lat, long, $t$ ). Equation 1 defines risk $R$ and security $S$ from a logic perspective. The t-norm $\cap_{\min }$ is a fuzzy logic AND-operator [58] (here: minimum value of $H$ and $V$ ). The operator heuristically transforms fuzzy sets of $H=[0,1]$ and $V=[0,1]$ into sets of $R=[0,1]$ or $S=[0,1]$. This logic rule can be semantically expressed as follows: 
There are two advantages of defining risks logically. First, humans tend to have no records on impacts of extreme events (low-probability) such as earthquakes. Thus, the frequency $F$ or occurrence time is associated with a high uncertainty $\delta F$. But, humans have an understanding (feeling) on possible hazard intensities $I$ and impacts or scenarios. Hence, a logic approach is more intuitive and useful until more data are observed and empirically acquired. Second, the approach $R=H \times V$ of simply multiplying $H$ and $V$, as suggested by the United Nations, [56] is a legitimate way, but the algebraic product is under-estimating risks for non-extreme hazard or vulnerability values. For example, a monitored relative hazard level is "medium" $H=0.51$ and the relative vulnerability is also "medium" $V=0.49$. The resulting risk would be "medium" as well with $0.51 \cap_{\min } 0.49=0.49$, following the logic approach. In contrast, the approach suggested by the UN would result in a much lower risk level of $0.51 \times 0.49=$ 0.25 . This leads to an underestimation of the expected risk and an overestimation of the expected human security.

Generally, the risk and security uncertainties associated with human-triggered earthquakes are certainly high. But, they are much smaller in comparison to uncertainties associated with nature-triggered earthquakes, because location and production/operation/construction plans are accurately and precisely known. Thus, triggering stress perturbations at potential earthquake nucleation points can be modeled in space and time, while existing population densities and economic assets are also known.

Gaussian error propagation shows that risk uncertainty $\delta R$ and security uncertainty $\delta S$ are smaller when applying a logic approach

$$
\begin{aligned}
\delta S & =\delta R \\
& =\delta H \cap_{\min } \delta V,
\end{aligned}
$$

in comparison to the traditional approach

$$
\begin{aligned}
& \delta R=\frac{(\delta H+\delta V)}{R}, \\
& \delta S=(\delta H+\delta V) \\
& S
\end{aligned}
$$

Equations 3 and 4 show that the traditional approach of determining geohazard risks results in higher uncertainties than a logic approach with implications for further risk mitigation strategies or tactics. Thus, a risk-averse or risk-acceptant decision maker would decide for a logic approach of calculating expected risk and security levels.

Finally, the largest uncertainty of the resulting risk/security results mainly forms the natural system, including the geological situation and the knowledge about historic earthquakes, i.e., paleo-seismicity. Policy tools could be implemented, for example, if regions of potential earthquake nucleation points can be identified. Scientific efforts could concentrate in those regions to evaluate the natural system (source of geohazard) more precisely (see figure 4). In case of the Sünna and Völkershausen earthquakes, policy tools were implemented in the early 1990s to mitigate the hazard level for new earthquakes and mining collapses. Since 1993 more than 200 million US\$ (2009 value) were invested to refill the underground excavations. 
COPY: Achieving Environmental Security: Ecosystem Services and Human Welfare.

\section{Risk Mitigation and Reduction Strategies}

Expected risks associated with human-triggered earthquakes depend on both the hazard (of the potentially threatening phenomenon) and the vulnerability (see eq. 1). Two types of strategies exist with several tactical measures to mitigate expected risks and improve human security. A strategy is a defined way that has to be taken to reach a required goal of minimizing risk (maximizing human security) [3]. Tactics can be understood as those measures that follow such a defined way. Carl von Clausewitz formulated a "theory-law-balanced" framework, which is comparable to today's concepts of social science [2]. Furthermore, von Clausewitz argues that theories are more appropriate to develop strategies, whereas laws are applicable for tactical (operational) measures. Based on von Clausewitz's framework, risk mitigation strategies and tactics include, for example:

- $\quad$ mitigate/reduce potential hazards

- understand geological and tectonic conditions that support planned geoengineering activities (e.g., stress perturbations),

- perform geomechanical long-term models,

- conduct geophysical monitoring (e.g., [57])

- generate hazard maps (see figure 4),

- change the operation/production technology accordingly,

- $\quad$ mitigate/reduce existing/future vulnerabilities

- create effective and efficient emergency response plans and institutions,

- $\quad$ shift geoengineering activities away from urban areas,

- $\quad$ shift urban areas away from geoengineering activities,

- reinforce building structures,

- change building codes,

- change urban planning.

Tactical measures to mitigating hazard levels (i.e., threat) follow an "offensive strategy" to reducing the severity of the threatening seismic event. On the other hand, measures that mitigate vulnerabilities follow a "defense strategy," while responding to and preventing the threat. In addition, many of von Clausewitz's proposed strategies/tactics are defense oriented. Even more, he argues that defense is a stronger form of war, because the time that passes until a threat occurs accumulates to the credit of the defender: "beati sunt possidentes" (fortunate are those in possession) [3]. The available time until an earthquake occurs can be used to implement policy tools to increasing vulnerabilities and, thus, improving the overall human security (e.g., to reinforce building structures). Geohazard reduction measures, on the other hand, can be applied only to human-triggered threatening events. Impacts of nature-triggered geohazards (e.g., volcanic eruptions, tsunamis), allow only vulnerability reduction measures to ensure human security.

\section{Future Hazard Hotspots}

The accelerating global climate change and an increasing global energy demand with expected supply shortages force economies and societies to find alternative energy 
COPY: Achieving Environmental Security: Ecosystem Services and Human Welfare.

sources. On top of this they try to reduce their greenhouse gas emissions, which are thought to increase global warming. This, in turn, has been stimulating entrepreneurs since the beginning of the 21 st century to find new solutions and options a) to producing larger amounts of geothermal energy from deep underground and b) to sequestering carbon dioxide $\left(\mathrm{CO}_{2}\right)$ deep underground to achieve a reduction of atmospheric emissions. Besides existing geoengineering practices (e.g., artificial water reservoir impoundments or deep mining), it can be anticipated that new earthquake hazards increase in the vicinity of geothermal power plants and carbon capture and sequestration (CCS) sites.

\subsection{Geothermal Energy Production}

Geothermal energy production is proposed as an alternative energy source, due to an increasing global energy demand and expected shortages, in particular, of hydrocarbon energy supplies throughout the 21 st century. Both the extraction of hot water in deep boreholes and the reinjection of cold water in distant boreholes can generate a geothermal energy production cycle until the hot rocks deep underground (2-6km) cool down and the thermal energy source ceases. The production cycle, however, can be perturbed when too much fluid is extracted (see figure 5) or injected [65]. Large amounts of water masses can be removed or accumulated during the lifespan of a deep geothermal power plant. These water mass imbalances, again, alter the stress states of the Earth's crust and can set off earthquakes. Several examples have been reported, including, for example, the M3.8 Basel earthquake in Switzerland in 2006 (see table 1), the M3.2 Larderello-Travale earthquake in Italy in 1982 [66], and theM3.0 ChipilapaAhuachapan earthquake in El Salvador in 1991 [67]. 


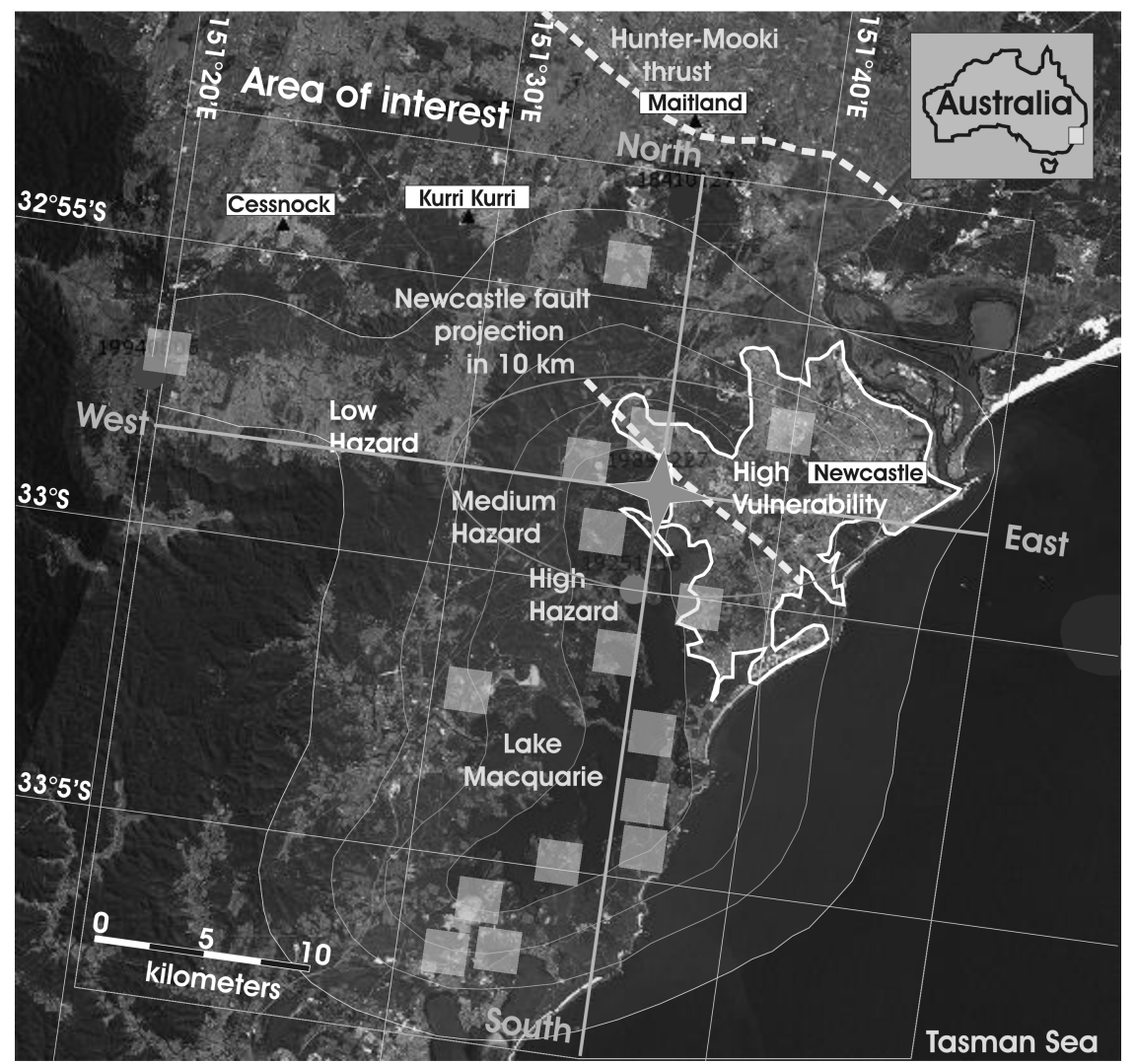

Figure 4. Hazard map of potential coal mining-triggered earthquakes in an area of the Newcastle coalfield in New South Wales (Australia). The squares show the locations of underground coalmines in approx. $500 \mathrm{~m}$ depth. The resulting stress changes in the Earth's crust are qualitatively indicated by the labels "Low Hazard," "Medium Hazard," and "High Hazard." The projection of the fault that ruptured during the 1989 M5.6 Newcastle earthquake (star) in about 10km depth intersects with the area of high and medium earthquake hazard. Furthermore, the urbanized area of the city of Newcastle ("High Vulnerability") also coincides with the area of medium and high hazard. This indicates why the Newcastle earthquake had such high impacts on the human security $[23,4]$.

The Salton Sea geothermal power plant in southern California might be one of the new hot spots of triggering a major earthquake. The power plant is placed in an area that interconnects two major faults, the San Andreas Fault (SAF) $<20 \mathrm{~km}$ in the north and the Imperial Fault (IF) $<20 \mathrm{~km}$ in the south (see figure 6 ). This interconnection zone is called Brawley Seismic Zone and has been characterized by an increasing seismicity for several decades. Between 1982 and 2007, 300 million tonnes of underground water were extracted from this area. The current and expected mass imbalance caused by the geothermal power plant is of concern, since the U.S. Geological Survey identified the southern part of SAF as the most likely source of a very large earthquake $(M>7)$ in California in the very near (but unknown) future. Despite the fact that tectonic forces dominate the seismic activity in the vicinity of the Salton Sea geothermal power plant, any additional triggering stress perturbations on SAF could advance the clock of such a major event. This would reduce the time to implement proper policy tools to ensure human security. Observations show that the seismicity increased in the Brawley Seismic Zone with the production of geothermal energy (see figure 5). The number of 
earthquakes $\left(\mathrm{M}_{\mathrm{w}}>3\right)$ per area in the Brawley Seismic Zone is twice the event rate per area in the $100 \times 200 \mathrm{~km}^{2}$ (North-South $\times$ East-West) surrounding region of southern California and northern Mexico. The correlation coefficient between the net water extraction and the event rate is 0.59 ; again more than twice the correlation coefficient in its vicinity $(0.20)$.

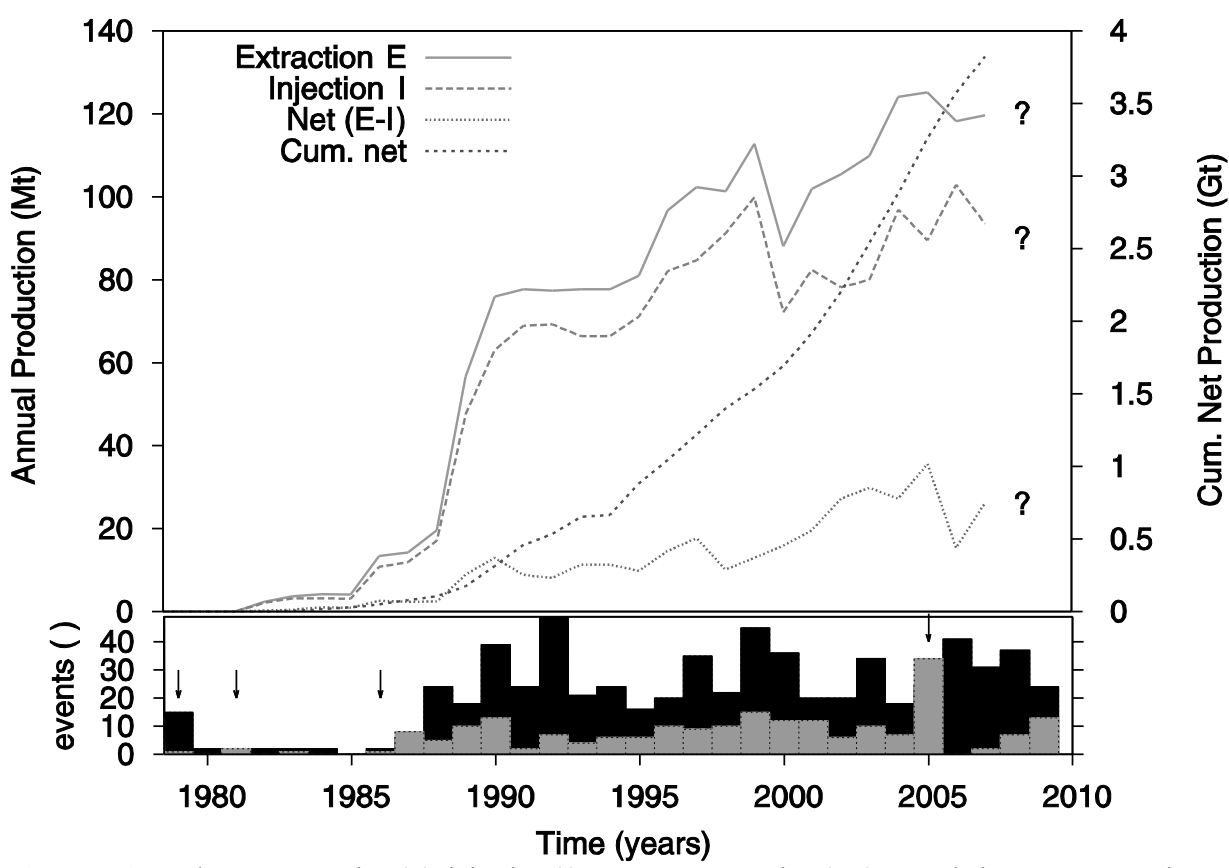

Figure 5. Annual water extraction (E), injection (I), net water extraction (E-I), cumulative water extraction at the Salton Sea geothermal power plant in southern California (USA) between 1982 and 2008 (production data are available through the California Department of Conservation) and the event rate of earthquakes (events per year) of the Brawley Seismic Zone (gray bars) in comparison to the $100 \times 200 \mathrm{~km}^{2}$ (NorthSouth $\times$ East-West) surrounding region of southern California and northern Mexico (black bars). The relationship between water extraction/injection and the event rate in the Brawley Seismic Zone shows that the number of earthquakes has been increasing with the amount of net water extraction. The black arrows indicate magnitude 5 events that occurred between 1978 and 2009. (Seismic data are available through IRIS - Incorporated Research Institutions for Seismology.)

\section{2. $\mathrm{CO}_{2}$ Sequestration}

The amount of $\mathrm{CO}_{2}$ that would need to be injected in geological sinks, such as deep saline aquifers to achieve a significant reduction of atmospheric emissions, is very large. For example, a 1000 megawatt (MW) coal-fired power plant emits approximately $30,000 \mathrm{t}$ of $\mathrm{CO}_{2}$ per day, 10 million tonnes (Mt) per year, and hence approximately $300 \mathrm{Mt}$ over a typical lifetime of 30 years. The resulting mass change of $\mathrm{CO}_{2}$ injected underground in an area of $100 \mathrm{~km}^{2}$ or more [59] is enough to change the vertical in situ stress in the Earth's crust by $0.01 \mathrm{MPa}$ in a depth of $10 \mathrm{~km}$. Fluid pressure increases in excess of $0.1 \mathrm{MPa}$ would extend over an area of more than 2,500 $\mathrm{km}^{2}$ [59] in shallow depth $(<2.5 \mathrm{~km})$. These stress alterations exceed tidal stress levels of the sun and the moon and can advance the clock of earthquakes or trigger new events. Several geological CCS options exist, including injections in depleted crude oil 
and natural gas reservoirs [60], in coal beds for methane production [61], in saline aquifers [62], or in rocks that enhance mineralization of $\mathrm{CO}_{2}$ [63]. None of these options ensures an immediate trapping of the liquid $\mathrm{CO}_{2}$. The injected bubble migrates through pores, fractures, and faults [64] and migrates toward the surface due to its buoyancy. Thus, regions near injection sites are prone to a higher earthquake hazard. Offshore carbon capture and sequestration (CCS) activities can set off earthquakes. Such tremors can trigger submarine landslides, which, in turn, may cause tsunamis that put coastal regions at multi-hazard risks.

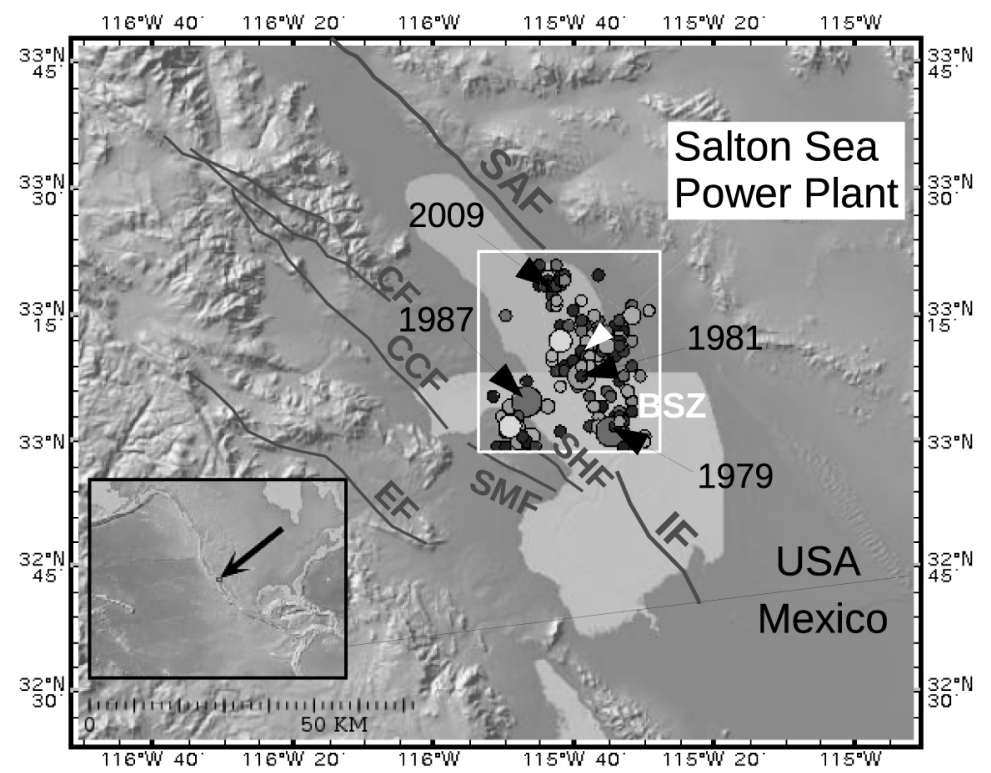

Figure 6. Geological and seismological situation near the Salton Sea geothermal power plant in southern California (USA). The white box indicates the sampling area of earthquakes with moment magnitudes $\mathrm{M}_{\mathrm{w}}>3$ surrounding the injection and extraction boreholes of the power plant between 1978 and 2009. The largest magnitude 5 earthquakes are indicated by their years of occurrence. Major faults are shown as dark lines, including San Andreas Fault (SAF), Imperial Fault (IF), Superstition Hills Fault (SHF), Superstition Mountain Fault (SMF), Coyote Creek Fault (CCF), Clark Fault (CF), and Elsinore Fault (EF). The white highlighted region illustrates the Brawley Seismic Zone (BSZ).

\section{Conclusion}

Human-triggered earthquakes are an environmental hazard that has been exponentially growing since the 20th century. This type of geohazard is associated with large-scale geoengineering activities (e.g., mining, water reservoir impoundment, oil/gas production, and fluid injection/extractions). It can have serious implications for longterm human security. Historical data specifically show that such activities can advance the clock of natural seismic cycles or trigger new earthquakes. These seismic events, in turn, can start after decades and can last for decades.

Historical evidence has also shown that the most common strategy to cope with human-triggered earthquakes is reconstruction and not risk reduction, which might be explained by the disposition effect, a behavioral bias of decision makers. The effect might be explained by the prospect theory [68] and describes that decision makers are 
more willing to recognize potential gains and unwilling to recognize potential losses. Thus, true risk reduction strategies that address hazard prevention and vulnerability mitigation need more scientific, legal, and public attention, including urban planning adaptation and hazard-mapping.

Modern geotechnologies utilized within urban areas are going to increase worldwide, including artificial water reservoirs, mining, carbon sequestration, or deep geothermal energy production. Countries abundant in natural resources will increase the exploitation of their resources by extractive industries (e.g., hydrocarbon, hydrological, geothermal). Thus, due to the continuing increase in productivity and the size of global geoengineering activities, it can be anticipated that human-triggered earthquakes will continue affecting human security in both developing and developed countries.

\section{Acknowledgement}

I would like to thank, in particular, Peter Liotta, whose tiredless efforts made this book possible. I also want to thank Teressa Haas and other scholars at the Pell Center for their editorial work on my chapter. Finally, I am grateful for the feedback from two anonymous reviewers in social science and seismology who asked tough questions to improve my work.

\section{References}

[1] Human Development Report, United Nations Development Programme, 1994.

[2] J. Klinger, The Social Science of Carl von Clausewitz, Springer, Dordrecht, 2006.

[3] C. von Clausewitz, On War, Princeton University Press, Princeton, NJ, 1976.

[4] C.D. Klose, Mine water discharge and flooding: A cause of severe earthquakes, Mine Water and the Environment 26 (2007), 172-180.

[5] L. Seeber, Mechanical pollution, Seismological Research Letters 73 (2002), 315-317.

[6] C.D. Klose, First global catalog of human-triggered earthquakes (status quo 2005), Seismological Society of America-Eastern Section, Ottawa, Canada, 1-4 October 2006.

[7] L. Seeber, G. Ekström, S.K. Jain, C.V.R. Murty, N.C. Chandak, and J.G. Armbruster, The 1993 Killari earthquake in central India: A new fault in Mesozoic basalt flow? Journal of Geophysical Research 101 (1996), 8543-8560.

[8] J.R. Kayal and S. Mukhopadhyay, Seismic tomography structure of the 1993 Killari earthquake, Bulletin of the Seismological Society of America 92 (2002), 2036-2039.

[9] S.K. Guha, P.D. Gosavi, B.N.P. Agarwal, J.G. Padale, and S.C. Marwadi, Case histories of some artificial crustal disturbances, Engineering Geology 8 (1974), 59-77.

[10] H.K. Gupta and B.K. Rastogi, Investigations of the behavior of reservoir-associated earthquakes, Engineering Geology 8 (1974), 29-38.

[11] H.K. Gupta, The present status of the reservoir induced seismicity investigations with special emphasis on Koyna earthquakes, Tectonophysics 118 (1985), 257-279.

[12] H.K. Gupta, B.K. Rastogi, R.K. Chadha, P. Mandhal, and C.S.P. Sarma, Enhanced reservoir induced earthquakes in Koyna region, India, during 1993-95, Journal of Seismology 1 (1997), 47-53.

[13] P. Talwani, Seismotectonics of the Koyna-Warna area, India, Pure and Applied Geophysics 150 (1997), 511-550.

[14] B. Voight and C. Faust, Frictional heat and strength loss in some rapid landslides: Error correction and affirmation of mechanism for the Vaiont landslide, Geotechnique 42 (1992), 641-643.

[15] H-K. Gupta, A review of recent studies of triggered earthquakes by artificial water reservoirs with special emphasis on earthquakes in Koyna, India, Earth-Science Review 58 (2002), 279-310.

[16] V.V. Adushkin and A.E. Yudin, Seismicity in the oil field, Oil Field Review 12 (2000), 2-17.

[17] D.W. Simpson and W. Leith, The 1976 and 1984 Gazli, USSR, earthquakes-Were they induced? BSSA 75 (1985), 1465-1468. 
COPY: Achieving Environmental Security: Ecosystem Services and Human Welfare.

[18] V.M.R. Maury, J.-R. Grasso, and G.Wittlinger, Monitoring of subsidence and induced seismicity in the Lacq Gas Field (France): The consequences on gas production and field operation, Engineering Geology 32 (1992), 123-135.

[19] J.-R. Grasso, J.-P.Gratier, J.F. Gamond, and J.-C. Paumier, Stress transfer and seismic instability in the upper crust: Example of the western Pyrenees, Journal of Structural Geology 14 (1992), 915-924.

[20] C. Pequegnat, P. Gueguen, D. Hatzfeld, and M. Langlais, The French Accelerometric Network (RAP) and National Data Centre (RAP-NDC), Seismological Research Letters 70 (2008), 79-89.

[21] L. Driad-Lebeau, F. Lahaie, M. Al Heib, J.P. Josien, P. Bigarre, and J.F. Noirel, Seismic and geotechnical investigations following a rockburst in a complex French mining district, International Journal of Coal Geology 64 (2005), 66-78.

[22] L. Seeber, J.G. Armbruster, W.-Y. Kim, N. Barstrow, and C. Scharnberger, The 1994 Cacoosing Valley earthquake near Reading, Pennsylvania: A shallow rupture triggered by quarry unloading, Journal of Geophysical Research 103 (1998), 24, 505-24, 521.

[23] C.D. Klose, Geomechanical modeling of the nucleation process of Australia's 1989 Newcastle earthquake, Earth Planetary Science Letters 256 (2007), 547-553.

[24] A. McGarr, On a possible connection between three major earthquakes in California and oil production, Bulletin of Seismological Society of America 81 (1991), 948-970.

[25] J.R. Grasso, Mechanics of seismic instabilities induced by the recovery of hydrocarbons, Pure and Applied Geophysics 139 (1992), 507-534.

[26] G. Leydecker, Der Gebirgsschlag vom 13 März 1989 bei Völkershausen in Thüringen im Kalibergbaugebiet des Werratals, Geologisches Jahrbuch der Bundesanstalt für Geowissenschaften und Rohstoffe 55 E (1998), 99.

[27] E. Kellermann, Das Beben von Völkershausen: Der Gebirgsschlag im März 1989 und das Aufbegehren der Bevölkerung, Deutschland-Archiv 33 (2000).

[28] R. Kovach, Source mechanisms for Willmington oil field, California, subsidence earthquakes, Bulletin of Seismological Society of America 64 (1974), 699-711.

[29] R.F. Yerkes and R.O. Castle, Seismicity and faulting attributable to fluid extraction, Engineering Geology 10 (1970), 151-167.

[30] G. Drakatos, D. Papanastassiou, G. Papadopoulos, H. Skafida, and G. Stavrakakis, Relationship between the 13 May 1995 Kozani-Grevena (NW Greece) earthquake and the Polyphyto artificial lake, Engineering Geology 51 (1998), 65-74.

[31] Quake hit Greece, Phillipines, Indonesia, United States, Earthquake Engineering Research Institute Newsletter 29 (1995), 1-4.

[32] D. Tocher, The Hebgen Lake, Montana, earthquake of August 17, 1959, MST, Bulletin of Seismological Society of America 52 (1962), 153-162.

[33] I.J. Witkind, W.B. Myers, J.B. Hadley, W. Hamilton, and G.D. Fraser, Bulletin of Seismological Society of America 52 (1962) 163-180.

[34] F.W. Klein, Tidal triggering of reservoir-associated earthquakes, Engineering Geology 10 (1976), 197210.

[35] C.D. Klose, Coastal land loss and gain as potential earthquake trigger mechanism in SCRs, Eos Trans. AGU 88 (2007), Fall Meet. Suppl., Abstract T51D-0759.

[36] C. Bufe, F.W. Lester, K.M. Lahr, J.C. Lahr, L.C. Seekins, and T.C. Hanks, Oroville earthquakes: Normal faulting in the Sierra Nevada foothills, Science 192 (1976), 72-74.

[37] A. Ryall, W.A. Peppin, and J.D. Vanwormer, Field-seismic investigation of the August 1975 Oroville, California, earthquake sequence, Engineering Geology 10 (1976), 353-369.

[38] W.U. Savage, D. Tocher, and P.C. Birkhahn, A study of small aftershocks of the Oroville California, earthquake sequence of August 1975, Engineering Geology 10 (1976), 371-385.

[39] K. Rajendran and H.K. Gupta, Was the earthquake sequence of August 1975 in the vicinity of Lake Oroville, California, reservoir induced? Physics of the Earth and Planetary Interiors 44 (1986), 142148.

[40] J.H. Healy, W.W. Rubey, D.T. Griggs, and C.B. Raleigh, The Denver earthquakes, Science 161 (1968), $1301-1310$

[41] P. Knoll, The fluid-induced tectonic rock burst of March 13, 1989 in Werra potash mining district of the GDR (first results), Gerlands Breitr Geophys 99 (1990), 239-245.

[42] J.C. Pechmann, W.R.Walter, S.J. Nava, and W.J. Arabasz, The February 3, 1995, ML 5.1 seismic event in the Trona mining district of southwestern Wyoming, Seismological Research Letters 66 (1995), 2534.

[43] C.D. Klose and L. Seeber, Shallow seismicity in stable continental regions, Seismological Research Letters 76 (2007), 554-562.

[44] S.E. Hough, L. Seeber, and J.G. Armbruster, Intraplate triggered earthquakes: Observations and interpretation, Bulletin of the Seismological Society of America 93 (2003), 2212-2221. 
COPY: Achieving Environmental Security: Ecosystem Services and Human Welfare.

[45] S. Steacy, J. Gomberg, and M. Cocco, Introduction to special section: Stress transfer, earthquake triggering, and time-dependent seismic hazard, Journal of Geophysical Research 110 (2005), 1-12.

[46] N.M. Beeler and D.A. Lockner, Why earthquakes correlate weakly with the solid Earth tides: Effects of periodic stress on the rate and probability of earthquake occurrence, JGR 108 (2003), 2391.

[47] J. Townend and M.D. Zoback, How faulting keeps the crust strong, Geology 28 (2000), 399-402.

[48] K.H. Jacob, W.D. Pennigton, J. Armbruster, L. Seeber, and S. Farhatulla, Tarbela reservoir, Pakistan: A region of compressional tectonics with reduced seismicity upon initial reservoir filling, Bulletin of the Seismological Society of America 69 (1979) 1175-1192.

[49] S.H. Bland, E.S. O'Leary, E. Farinaro, F. Jasso, and M. Trevisan, Long-term psychological effects of natural disasters, Psychosomatic Medicine 58 (1996), 18-24.

[50] X-L. Lei, S-L. Ma, X-Z. Wen, J.R. Su, and F. Du, Integrated analysis of stress and regional seismicity by surface loading - A case study of Zipingpu reservoir, Seismology and Geology 30 (2008), 1046.

[51] C.D. Klose, The 2008 M7.9 Wenchuan earthquake-Result of local and abnormal mass imbalances? EOS Trans. AGU 89, (2008), Fall Meet. Suppl., Abstract U21C-08.

[52] C.D. Klose, Evidence for Surface Loading as Trigger Mechanism of the 2008 Wenchuan Earthquake, arXiv.org, [physics.geo-ph] (2010) 1007.2155v1. http://arxiv.org/abs/1007.2155

[53] A. Witze, The sleeping dragon, Nature 459 (2009), 153-157, doi:10.1038/459153a.

[54] R. Kerr and R. Stone, Seismology: A human trigger for the Great Quake of Sichuan? Science 323 (2009), 322, doi:10.1126/science.323.5912.322

[55] S. Lui, X. Huanga, L. Chen, H. Tang, T. Zhang, X. Lia, D. Li, W. Kuang, R.C. Chan, A. Mechelli, J.A. Sweeney, and Q. Gong, High-field MRI reveals an acute impact on brain function in survivors of the magnitude 8.0 earthquake in China, PNAS 106 (2009), 15412-15417.

[56] UNDRO, Natural Disasters and Vulnerability Analysis, Office of the United Nations Disaster Relief Coordinator, Report of Expert Group Meeting (9-12 July 1979), United Nations, Geneva, 1980.

[57] C.D. Klose, S. Loew, R. Giese, and G. Borm, Spatial predictions of geological rock mass properties based on in-situ interpretations of multi-dimensional seismic data, Engineering Geology 93 (2007), 99116.

[58] L.A. Zadeh, Fuzzy sets as a basis for a theory of possibility. Fuzzy Sets and Systems 1 (1978), 3-28.

[59] K. Pruess, Numerical studies of fluid leakage from a geologic disposal reservoir for $\mathrm{CO}_{2}$ show selflimiting feedback between fluid flow and heat transfer, Geophysical Research Letters 32 (2005), L14404.

[60] K. Jessen, A.R. Kovscek, and F.M. Orr, Increasing $\mathrm{CO}_{2}$ storage in oil recovery, Energy Conversion and Management 46 (2005), 293-311.

[61] J. Gale and P. Freund, Coal-bed methane enhancement with $\mathrm{CO}_{2}$ sequestration worldwide potential, Environmental Geosciences 8 (2001), 210-217.

[62] J.M. Nordbotten, M.A. Celia, and S. Bachu, Injection and storage of $\mathrm{CO}_{2}$ in deep saline aquifers: Analyistical solution for $\mathrm{CO}_{2}$ plume evolution during injection, Transp. Porous Med. 58 (2005), 339360.

[63] W.D. Gunter, E.H. Perkins, and I. Hutcheon, Aquifer disposal of acid gases: Modelling of water rock reactions for trapping of acid wastes, Applied Geochemistry 15 (2000), 1085-1095.

[64] Z.K. Shipton, J.P. Evans, D. Kirschner, P.T. Kolesar, A.P. Williams, and J. Heath, Analysis of $\mathrm{CO}_{2}$ leakage through "low-permeability" faults from natural reservoirs in the Colorado Plateau, east-central Utah, in S.J. Baines and R.H. Worden, eds., Geological Storage of Carbon Dioxide, Geological Society of London Special Publication 233, London, 2004.

[65] T. Kraft, P.M. Mai, S. Wiemer, N. Deichmann, J. Ripperger, P. Kästli, C. Bachmann, D. Fäh, J.Wössner, and D. Giardini, Enhanced geothermal systems: Mitigating risk in urban areas, Eos Trans. $A G U 90$ (2009), doi:10.1029/2009EO320001.

[66] F. Batini, R. Console, and G. Luongo, Seismological study of Larderello-Travale Geothermal area, Geothermics 14 (1985), 255-272.

[67] H. Fabriol and A. Beauce, Temporal and spatial distribution of the local seismicity in the ChipilapaAhuachapan geothermal area, El Salvador, Geothermics 26 (1997), 681-699.

[68] D. Kahneman and A. Tversky, Prospect theory: An analysis of decision under risk, Econometrica XLVII (1979), 263-291. 